\title{
First national intercomparison of solar ultraviolet radiometers in Italy
}

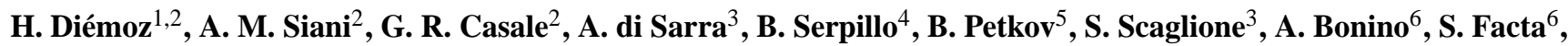 \\ F. Fedele ${ }^{7}$, D. Grifoni ${ }^{8}$, L. Verdi ${ }^{9}$, and G. Zipoli ${ }^{8}$ \\ ${ }^{1}$ ARPA Valle d'Aosta, Loc. Grande Charrière 44, 11020 Saint-Christophe, Italy \\ ${ }^{2}$ Sapienza - Univ. Roma, Department of Physics, Piazzale Aldo Moro 5, 00185 Roma, Italy \\ ${ }^{3}$ ENEA, Via Anguillarese 301, 00123 S. Maria di Galeria, Roma, Italy \\ ${ }^{4}$ ARPA Basilicata, Via della Fisica 18 C/D, 85100 Potenza, Italy \\ ${ }^{5}$ CNR-ISAC, Via Gobetti 101, 40129 Bologna, Italy \\ ${ }^{6}$ ARPA Piemonte, Via Jervis 30, 10015 Ivrea, Italy \\ ${ }^{7}$ ARPA Puglia, Corso Trieste 27, 70126 Bari, Italy \\ ${ }^{8}$ CNR-IBIMET/LaMMa, Via Giovanni Caproni 8, 50145 Firenze, Italy \\ ${ }^{9}$ APPA Bolzano, Via Amba Alagi 5, 39100 Bolzano, Italy
}

Received: 14 March 2011 - Published in Atmos. Meas. Tech. Discuss.: 11 May 2011

Revised: 26 July 2011 - Accepted: 25 August 2011 - Published: 31 August 2011

\begin{abstract}
A blind intercomparison of ground-based ultraviolet (UV) instruments has been organized for the first time in Italy. The campaign was coordinated by the Environmental Protection Agency of Aosta Valley (ARPA Valle d'Aosta) and took place in Saint-Christophe $\left(45.8^{\circ} \mathrm{N}, 7.4^{\circ} \mathrm{E}\right.$, $570 \mathrm{~m}$ a.s.1.), in the Alpine region, from 8 to 23 June 2010. It involved 8 institutions, 10 broadband radiometers, 2 filter radiometers and 2 spectroradiometers. Synchronized measurements of downward global solar UV irradiance at the ground were collected and the raw series were then individually processed by the respective operators on the base of their own procedures and calibration data. A radiative transfer model was successfully applied as an interpretative tool. The input parameters and output results are described in detail. The comparison was performed in terms of global solar UV Index and integrated UV-A irradiance against a wellcalibrated double monochromator spectroradiometer as reference. An improved algorithm for comparing broadband data and spectra has been developed and is discussed in detail. For some instruments, we found average deviations ranging from $-16 \%$ up to $20 \%$ relative to the reference and diurnal variations as large as $15 \%$ even in clear days. Remarkable deviations were found for the instruments calibrated in the manufacturers' facilities and never involved in field intercomparison. Finally, some recommendations to the UV operators based on the campaign results are proposed.
\end{abstract}

Correspondence to: H. Diémoz

(h.diemoz@arpa.vda.it)

\section{Introduction}

The last two decades have witnessed a worldwide diffusion of ground-based instruments for measuring the solar ultraviolet (UV) radiation reaching the Earth surface. Many radiometers have been employed to investigate the influence of atmospheric composition changes on solar UV irradiance at the ground (WMO, 2011) as well as to assess the related risks for the human health and the environment (UNEP, 2010).

Well calibrated ground-based networks on a continental and national level are also essential in order to monitor the effective behaviour of the solar UV radiation in the next years on a small spatial scale (McKenzie et al., 2011). This will help to control whether the Montreal Protocol targets are fulfilled and the model predictions are correct. Moreover, quality ground-based instruments, traceable to a common reference, allow to validate satellite data mainly over polluted locations (Lee-Taylor et al., 2010) or at sites with a complex orography.

However, high quality UV measurements are still a complex task. Possible UV trends are expected to be small and may be masked by natural cycles (Seckmeyer et al., 2001; Glandorf et al., 2005; Seckmeyer et al., 2009). Moreover, measurements carried out within monitoring networks, in particular when made with different instruments, should reveal actual environmental patterns and should not be biased by instrumental differences. Thus, a great effort must be dedicated to achieve the necessary accuracy, both in developing and in maintaining the instruments. Therefore, data processing, calibration procedures, quality assurance and quality

Published by Copernicus Publications on behalf of the European Geosciences Union. 
control (QA/QC) methods are of primary importance (Bernhard and Seckmeyer, 1999; di Sarra et al., 2002).

Special care has been dedicated to define useful guidelines for quality control of UV monitoring (Seckmeyer et al., 2008a; Webb et al., 2006). Travelling instruments have been developed (Gröbner et al., 2005) and several calibration facilities exist nowadays (Gröbner et al., 2006). Moreover, some instrument comparisons have been organized all over the world (Leszczynski et al., 1998; Bais et al., 2000; Hülsen and Gröbner, 2007; Lantz et al., 2008) and have proven to be very successful in pointing out instrumental malfunctioning or data processing inaccuracies.

Continuous monitoring of solar UV radiation in Italy began in the early 1990s (Casale et al., 2000). The relatively wide latitude range over which Italy extends and its large variety of environments, which is representative of the Mediterranean as well as the Alpine regions (Meloni et al., 2000), make solar measurements in this country very valuable. Furthermore, sun exposure among natives and tourists is very common in both work and leisure activities (Siani et al., 2008, 2009). Some Italian institutions have been involved in European projects (Seckmeyer et al., 2008b), COST Actions (Hülsen and Gröbner, 2007) and international campaigns (Gröbner et al., 2010) and several Regional Environmental Protection Agencies (ARPAs, see Table 1 for a list of the agencies acronyms) started a monitoring programme in the last few years. However, the existing Italian instrumentation is not being operated within an established national network and a common research programme has not yet been planned. Only few and limited comparisons have been already performed (Di Menno et al., 2002), while a comprehensive national intercomparison had never been organized so far. Hence, the results of this first campaign are fundamental to assess the overall accuracy of the Italian instrumentation and to take measures to improve it if needed. Moreover, the campaign gives also additional information about the effectiveness of different correction procedures and the accuracy of calibration coefficients.

Although this work involved instruments operated by Italian institutions, some results may be useful also for other operators. First, the variety of the radiometers participating to the campaign and the different calibration and processing procedures make the comparison representative of a wider community than the Italian one. Most radiometers (11 of 13) are commercialized worldwide. Thus, the comparison can provide a contribution to the knowledge about the general performance of narrow- and broad-band UV radiometers, their characteristics, their operation and limits. Furthermore, some radiometers participating to the campaign were calibrated few months before the comparison by their respective manufacturers. Thus, the results of the comparison may be useful to obtain some information about the effectiveness and the consistency of the calibration procedures adopted by the manufacturers. Finally, the paper presents an in-depth analysis of the algorithm used to compare broadband and
Table 1. List of participating agencies and their acronyms.

\begin{tabular}{|c|c|}
\hline Acronym & Agency full name \\
\hline ARPA Valle d'Aosta & $\begin{array}{l}\text { Regional Environmental Protection } \\
\text { Agency of Aosta Valley }\end{array}$ \\
\hline ARPA Piemonte & $\begin{array}{l}\text { Regional Environmental Protection } \\
\text { Agency of Piedmont }\end{array}$ \\
\hline ARPA Puglia & $\begin{array}{l}\text { Regional Environmental Protection } \\
\text { Agency of Apulia }\end{array}$ \\
\hline Sapienza Univ. Roma & Sapienza - University of Rome \\
\hline CNR-IBIMET & $\begin{array}{l}\text { Italian National Research Council - } \\
\text { Insitute of biometeorology }\end{array}$ \\
\hline LaMMa & $\begin{array}{l}\text { Laboratory for the environmental } \\
\text { monitoring and modeling } \\
\text { for a sustainable development }\end{array}$ \\
\hline CNR-ISAC & $\begin{array}{l}\text { Italian National Research Council - } \\
\text { Institute of Atmospheric Sciences and } \\
\text { Climate }\end{array}$ \\
\hline ENEA & $\begin{array}{l}\text { Italian National Agency for new } \\
\text { technologies, energy } \\
\text { and sustainable economic development }\end{array}$ \\
\hline ARPA Lazio & $\begin{array}{l}\text { Regional Environmental Protection } \\
\text { Agency of Latium }\end{array}$ \\
\hline APPA Bolzano & $\begin{array}{l}\text { Provincial Environmental Protection } \\
\text { Agency of Bolzano }\end{array}$ \\
\hline
\end{tabular}

spectral UV data, that can improve the theoretical basis of the methods previously reported in literature.

The paper is organized as follows: the participating instruments and the radiative transfer model are described in Sect. 2. Section 3 gives an overview of the campaign. Section 4 presents the methods used to compare measurements from different instruments. The results are shown and discussed in Sect. 5. Finally, conclusions are drawn in Sect. 6.

\section{Participating instruments}

All the instruments participating to the campaign provided measurements of global solar UV irradiance. A description of the Bentham reference spectroradiometer, the Brewer spectrophotometer, broadband and narrowband radiometers is given in the following along with information about calibration and processing procedures. Table 2 summarizes the participating instruments and agencies, the identification numbers (id) used in the campaign, the traceability and the corrections applied to the data.

\subsection{Bentham double monochromator spectroradiometer}

A commercially available Bentham DTMc300F spectroradiometer belonging to ARPA Valle d'Aosta was used as the reference of the comparison (id 00). Similar instruments 
Table 2. Instruments and agencies participating to the comparison campaign. The institute to which the measurements are traceable is stated (in parentheses, the name of the reference instrument or facility through which the traceability is reached). The traceability was specified for the model, too, since some parameters were fixed with reference to Bentham 5541.

\begin{tabular}{|c|c|c|c|c|c|c|c|c|}
\hline Id & Agency & Instrument & Ser. Num. & $\begin{array}{l}\text { Type of } \\
\text { meas. }\end{array}$ & Traceability & $\begin{array}{l}\text { Calib. } \\
\text { date }\end{array}$ & Corrections & $\begin{array}{l}\text { Temp. } \\
\text { stab. }\end{array}$ \\
\hline 00 & $\begin{array}{l}\text { ARPA } \\
\text { Valle d'Aosta }\end{array}$ & $\begin{array}{l}\text { Bentham } \\
\text { DTMc300F }\end{array}$ & 5541 & Spectral irr. & $\begin{array}{l}\text { PTB } \\
\text { (QASUME) }\end{array}$ & 2010 & SHICrivm & $\mathrm{Y}$ \\
\hline 01 & $\begin{array}{l}\text { ARPA } \\
\text { Valle d'Aosta }\end{array}$ & $\begin{array}{l}\text { Kipp\&Zonen } \\
\text { UV-S-AE-T }\end{array}$ & 000526 & $\begin{array}{l}\text { Broadband } \\
\text { irr. (UV-A, } \\
\text { UV-E) }\end{array}$ & $\begin{array}{l}\text { PTB } \\
\text { (Bentham 5541) }\end{array}$ & 2010 & $\begin{array}{l}\text { Spectral, angular } \\
\text { (matrix) }\end{array}$ & $\mathrm{Y}$ \\
\hline 02 & $\begin{array}{l}\text { ARPA } \\
\text { Valle d'Aosta }\end{array}$ & $\begin{array}{l}\text { Kipp\&Zonen } \\
\text { UV-S-AE-T }\end{array}$ & 040618 & $\begin{array}{l}\text { Broadband } \\
\text { irr. (UV-A, } \\
\text { UV-E) }\end{array}$ & $\begin{array}{l}\text { PTB } \\
\text { (Bentham 5541) }\end{array}$ & 2010 & $\begin{array}{l}\text { Spectral, angular } \\
\text { (matrix) }\end{array}$ & $\mathrm{Y}$ \\
\hline 03 & $\begin{array}{l}\text { ARPA } \\
\text { Valle d'Aosta }\end{array}$ & $\begin{array}{l}\text { Yankee Env. } \\
\text { Syst. UVB-1 }\end{array}$ & 020528 & $\begin{array}{l}\text { Broadband } \\
\text { irr. (UV-E) }\end{array}$ & $\begin{array}{l}\text { PTB } \\
\text { (Bentham 5541) }\end{array}$ & 2010 & $\begin{array}{l}\text { Spectral, angular } \\
\text { (matrix) }\end{array}$ & $\mathrm{Y}$ \\
\hline 04 & $\begin{array}{l}\text { ARPA } \\
\text { Piemonte }\end{array}$ & $\begin{array}{l}\text { Kipp\&Zonen } \\
\text { UV-S-AE-T }\end{array}$ & 080003 & $\begin{array}{l}\text { Broadband } \\
\text { irr. (UV-A, } \\
\text { UV-E) }\end{array}$ & $\begin{array}{l}\text { NIST } \\
\text { (Kipp\&Zonen) }\end{array}$ & 2009 & $\begin{array}{l}\text { Spectral, angular } \\
\text { (matrix) }\end{array}$ & $\mathrm{Y}$ \\
\hline 05 & ARPA Puglia & $\begin{array}{l}\text { Kipp\&Zonen } \\
\text { UV-S-AE-T }\end{array}$ & 080005 & $\begin{array}{l}\text { Broadband } \\
\text { irr. (UV-A, } \\
\text { UV-E) }\end{array}$ & $\begin{array}{l}\text { NIST } \\
\text { (Kipp\&Zonen) }\end{array}$ & 2009 & $\begin{array}{l}\text { Spectral, angular } \\
\text { (matrix) }\end{array}$ & $\mathrm{Y}$ \\
\hline 06 & $\begin{array}{l}\text { Sapienza } \\
\text { Univ. Roma }\end{array}$ & $\begin{array}{l}\text { Yankee Env. } \\
\text { Syst. UVB-1 }\end{array}$ & 970827 & $\begin{array}{l}\text { Broadband } \\
\text { irr. (UV-E) }\end{array}$ & $\begin{array}{l}\text { PTB } \\
\text { (QASUME) }\end{array}$ & 2006 & $\begin{array}{l}\text { Spectral, angular } \\
\text { (matrix) }\end{array}$ & $\mathrm{Y}$ \\
\hline 07 & $\begin{array}{l}\text { CNR-IBIMET/ } \\
\text { LaMMa }\end{array}$ & $\begin{array}{l}\text { Solar Light } \\
501 \mathrm{~A}\end{array}$ & 5790 & $\begin{array}{l}\text { Broadband } \\
\text { irr. (UV-E) }\end{array}$ & $\begin{array}{l}\text { PTB } \\
\text { (QASUME) }\end{array}$ & 2008 & $\begin{array}{l}\text { None } \\
\text { (abs. factor) }\end{array}$ & $\mathrm{Y}$ \\
\hline 08 & $\begin{array}{l}\text { ENEA and } \\
\text { ARPA Lazio }\end{array}$ & $\begin{array}{l}\text { Solar Light } \\
501 \mathrm{~A}\end{array}$ & 13126 & $\begin{array}{l}\text { Broadband } \\
\text { irr. (UV-E) }\end{array}$ & $\begin{array}{l}\text { NIST } \\
\text { (Brewer \#123) }\end{array}$ & 2010 & $\begin{array}{l}\text { Spectral, angular; } \\
\text { Bodhaine et al. } \\
\text { (1998) }\end{array}$ & $\mathrm{Y}$ \\
\hline 09 & APPA Bolzano & $\begin{array}{l}\text { Solar Light } \\
\text { digital } 501\end{array}$ & 3733 & $\begin{array}{l}\text { Broadband } \\
\text { irr. (UV-A) }\end{array}$ & $\begin{array}{l}\text { NIST } \\
\text { (Solar Light) }\end{array}$ & 2010 & $\begin{array}{l}\text { Spectral } \\
\text { (fixed factor) }\end{array}$ & $\mathrm{Y}$ \\
\hline 10 & APPA Bolzano & $\begin{array}{l}\text { Solar Light } \\
\text { digital } 501\end{array}$ & 2717 & $\begin{array}{l}\text { Broadband } \\
\text { irr. (UV-E) }\end{array}$ & $\begin{array}{l}\text { NIST } \\
\text { (Solar Light) }\end{array}$ & 2010 & $\begin{array}{l}\text { Spectral } \\
\text { (fixed factor) }\end{array}$ & $\mathrm{Y}$ \\
\hline 11 & $\begin{array}{l}\text { ARPA } \\
\text { Valle d'Aosta }\end{array}$ & $\begin{array}{l}\text { Kipp\&Zonen } \\
\text { Brewer MKIV }\end{array}$ & 66 & $\begin{array}{l}\text { Total ozone } \\
\text { and spec- } \\
\text { tral irr. }\end{array}$ & $\begin{array}{l}\text { PTB } \\
\text { (QASUME) }\end{array}$ & 2010 & $\begin{array}{l}\text { Angular, straylight, } \\
\text { temperature, } \\
\text { SHICrivm }\end{array}$ & $\mathrm{N}$ \\
\hline 12 & CNR-ISAC & $\begin{array}{l}\text { ISAC UV-RAD } \\
\text { filter rad. }\end{array}$ & N.A. & $\begin{array}{l}\text { Narrowband } \\
\text { irr. (7 ch.) }\end{array}$ & $\begin{array}{l}\text { PTB } \\
\text { (Bentham 5541) }\end{array}$ & 2006 & None & $\mathrm{Y}$ \\
\hline 13 & $\begin{array}{l}\text { ENEA and } \\
\text { ARPA Lazio }\end{array}$ & $\begin{array}{l}\text { ENEA F-RAD } \\
02 \text { filter rad. }\end{array}$ & N.A. & $\begin{array}{l}\text { Narrowband } \\
\text { irr. (13 ch.) }\end{array}$ & $\begin{array}{l}\text { NIST } \\
\text { (Brewer \#123) }\end{array}$ & 2010 & None & $\mathrm{Y}$ \\
\hline 14 & $\begin{array}{l}\text { ARPA } \\
\text { Valle d'Aosta }\end{array}$ & $\begin{array}{l}\text { libRadtran } 1.5 \\
\text { (model) }\end{array}$ & N.A. & Spectral irr. & $\begin{array}{l}\text { PTB } \\
\text { (Bentham 5541) }\end{array}$ & $\begin{array}{l}2008- \\
2010\end{array}$ & N.A. & N.A. \\
\hline
\end{tabular}

were described in detail elsewhere (Gröbner et al., 2005). The original optics were replaced with a PTFE special shaped diffuser (CMS-Schreder, Model UV-J1002), which is temperature-stabilized and characterized by a nearly perfect angular response (Schreder et al., 1998), so that no angular correction is needed. A spectral scan from 290 to $400 \mathrm{~nm}$ every $0.25 \mathrm{~nm}$ takes about $3 \mathrm{~min}$ and was repeated every $5 \mathrm{~min}$ throughout the campaign.
The spectroradiometer calibration is regularly performed by ARPA Valle d'Aosta using a triad of $200 \mathrm{~W}$ QHT lamps calibrated at the Physikalisch-Meteorologisches Observatorium Davos - World Radiation Center (PMOD-WRC) with reference to the QASUME scale traceable to PTB (Gröbner and Sperfeld, 2005). The lamps and the diffuser are fitted in a portable field calibrator. An active feedback loop kit consisting in a calibrated shunt, a programmable power 


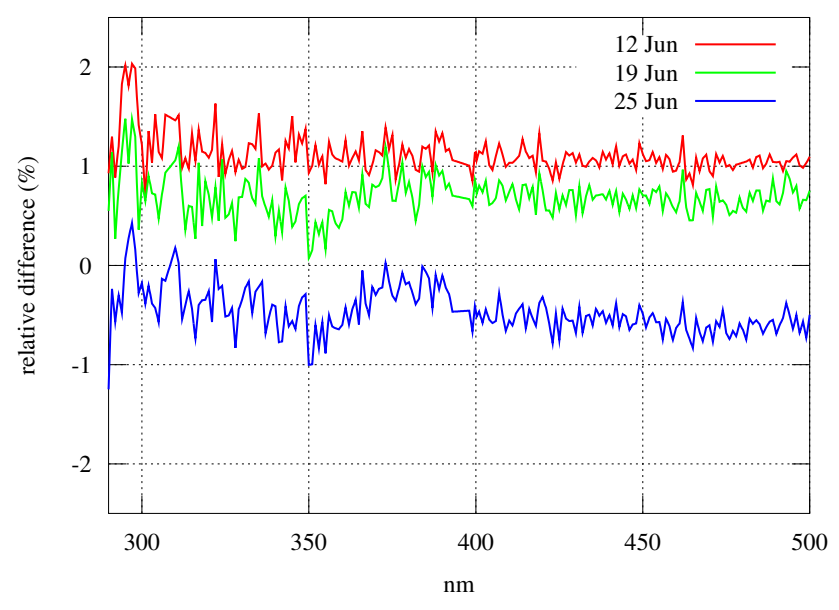

Fig. 1. Percentage variations of the spectroradiometer spectral responsivity relative to the first calibration in the campaign (4 June 2010). Every calibration curve is obtained as an average of the responsivities measured with three lamps.

supply (Xantrex XPD 33-16) and a digital multimeter (Agilent $34970 \mathrm{~A}$ ) controls the $6.300 \mathrm{~A}$ current feeding the calibrator with an uncertainty lower than $1 \mathrm{~mA}$. The spectroradiometer was compared to QASUME in 2009 showing an average offset of $0 \%$ and diurnal variations below $2 \%$ on clear sky days (http://www.pmodwrc.ch/euvc/euvc.php? topic=qasume_audit). Table 3 summarizes the combined radiometric uncertainty calculated for different wavelengths according to Gröbner et al. (2005); Bernhard and Seckmeyer (1999) and the Guide to the expression of Uncertainty in Measurement (BIPM et al., 2008).

The spectroradiometer was calibrated at the beginning and at the end of the comparison. In addition, two intermediate calibrations were performed weekly during the campaign. Figure 1 presents the variations of the spectral responsivity, which are not strictly a drift (the responsivity measured during the first calibration, used as a reference for the following, is lower than the second and similar to the third). The changes are to ascribe to the instrumental instability $(0.4 \%$ uncertainty, calculated assuming a rectangular probability distribution) and to the heating of the diffuser during the calibration (1\% uncertainty). The combined uncertainty originating from the two factors is higher than the observed variability. In order to reduce the errors caused by a wavelength misalignment, the spectra were processed with the SHICrivm package (Williams et al., 2003) using the instrumental slit function (measured with a He-Cd laser in 2009), deconvoluted and then reconvoluted using a triangular slit function (FWHM $1 \mathrm{~nm}$ ).

The total combined uncertainty is reported in Table 4 for different wavelengths and solar zenith angles.
Table 3. Radiometric uncertainty (\%) of the spectroradiometer. The total radiometer uncertainty is calculated as the squared sum of the different contributions. Coverage factor is marked with $K$.

\begin{tabular}{lcc}
\hline Contribution & $300 \mathrm{~nm}$ & $310-400 \mathrm{~nm}$ \\
\hline Lamp certificate (PMOD-WRC) & 2.3 & 2.3 \\
Instability & 0.4 & 0.4 \\
Statistic noise & 0.2 & 0.1 \\
Non-linearity & 0.5 & 0.5 \\
Current & 0.1 & 0.1 \\
Lamp aging & 0.5 & 0.5 \\
Wavelength misalignment & 0.1 & 0.1 \\
Heating of the diffuser & 1.0 & 1.0 \\
\hline Total $(K=1)$ & 2.7 & 2.7 \\
Expanded $(K=2)$ & 5.4 & 5.4 \\
\hline
\end{tabular}

\subsection{Brewer spectrophotometer}

A detailed description of the Brewer spectrophotometer and its principles of operation is provided by Kerr et al. (1980). The Brewer MKIV \#066 (id 11) has been measuring total column ozone (which is necessary for the spectral corrections of several broadband radiometers and as an input parameter to the model) for the campaign period. It was also included in the comparison as a tested instrument to measure solar UV irradiance.

Global irradiance spectra from 290 to $325 \mathrm{~nm}$ in steps of $0.5 \mathrm{~nm}$ were recorded every $30 \mathrm{~min}$. Even though it was possible to synchronize Brewer and Bentham spectral measurements wavelength by wavelength (as usually done during the regular Brewer calibrations against the Bentham, see below), we decided to give priority to collect a large number of Bentham measurements and to compare the data recorded by the two instruments as described in Sect. 4. The Brewer slit function is nearly triangular with a FWHM of about $0.63 \mathrm{~nm}$ (measured with a He-Cd laser in 2009). The algorithm developed by Cheymol and De Backer (2003), together with data from an in-situ Langley Plot calibration, is regularly employed to retrieve the aerosol optical depth (AOD) at 320 and $453 \mathrm{~nm}$ from clear-sky UV direct irradiance. The Ångström coefficients can then be estimated from measurements at these two wavelengths, according to Gröbner and Meleti (2004). The AOD and the Ångström coefficients are later included in the radiative transfer calculations.

The global irradiance scale of the Brewer is calibrated monthly against the ARPA Valle d'Aosta Bentham spectroradiometer by recording synchronous spectra during several clear days. Every two years, the Brewer is compared to the QASUME travelling standard. The spectra from the Brewer are corrected for its angular response, temperature, straylight and wavelength shifts. The ozone scale is calibrated with reference to the travelling standard \#017 from International Ozone Services every two years. 
Table 4. Total uncertainty $(\%)$ of the spectroradiometer. The total radiometer uncertainty is calculated as the squared sum of the different contributions.

\begin{tabular}{lcccc}
\hline Contribution & $300 \mathrm{~nm} 50^{\circ}$ & $300 \mathrm{~nm} 75^{\circ}$ & $310-400 \mathrm{~nm} 50^{\circ}$ & $310-400 \mathrm{~nm} 75^{\circ}$ \\
\hline Radiometric uncertainty & 2.7 & 2.7 & 2.7 & 2.7 \\
Diffuser temperature & 0.6 & 0.6 & 0.6 & 0.6 \\
Angular response & 0.4 & 0.4 & 0.8 & 0.8 \\
Non-linearity & 0.5 & 0.5 & 0.5 & 0.5 \\
Instability & 0.4 & 0.4 & 0.4 & 0.4 \\
Statistic noise & 0.8 & 4.6 & 0.3 & 0.9 \\
Wavelength misalignment & 2.1 & 2.4 & 0.9 & 0.9 \\
\hline Total $(K=1)$ & 3.6 & 5.9 & 3.0 & 6.2 \\
Expanded $(K=2)$ & 7.2 & 12 & 6.0 & 6.4 \\
\hline
\end{tabular}

\subsection{Broadband radiometers}

Ten broadband filter radiometers (id 01-10) participated to the comparison campaign. The output voltage of instruments 01-08, roughly proportional to the weighted irradiance to be measured (details are provided in the next paragraph), has been recorded with a digital programmable multimeter. A sampling time of $10 \mathrm{~s}$ was chosen for analog measurements. Data were collected also at night-time for finding electrical instabilities and calculating a zero-offset for each instrument. Two radiometers (id 09-10) were digital models equipped with their own acquisition systems, which recorded the (averaged) data at a maximum frequency of one value every $5 \mathrm{~min}$. Four double-band radiometers measured simultaneously UVA and erythemally weighted irradiance in two distinct channels. The remaining were single-band models (erythemal weighting). All broadband instruments were temperaturestabilized.

\subsection{Calibration and processing of broadband radiometers}

Ideally, the output voltage of the broadband radiometers should be perfectly proportional to the convolution of the solar spectral irradiance with a weighting curve, namely the sensitivity of the human skin (erythemal action spectrum, CIE, 1998; Webb et al., 2011) or the UV-A (315-400 nm) unitary function (CIE, 1999). In that case, an absolute calibration factor could be assessed to convert the voltage to the irradiance. However, the instrumental spectral sensitivity always differs from the action spectrum. Moreover, the angular response does not perfectly coincide with a cosine function. The induced errors may be relatively high and many methods can be applied to the recorded data to overcome the problem. Some of them are described in the following.

Data obtained by some instruments (id 01-06) were reprocessed by their respective agencies with a multiplicative factor stored in a table (matrix) depending on the total ozone, as measured by the Brewer throughout the campaign, and the solar zenith angle at the time of measurement (Webb et al., 2006). In such a way, spectral and angular corrections could be easily introduced. More precisely, data from radiometers 01-03 were processed with a matrix calculated by the owner agency: the spectral and angular characterization of those radiometers was performed by the PMOD-WRC, then the spectral and angular corrections were calculated by ARPA Valle d'Aosta using the libRadtran model. Finally, an absolute calibration factor was determined some weeks before the comparison campaign with reference to the Bentham spectroradiometer, following the procedure described by Hülsen and Gröbner (2007). Data from radiometers 04 and 05 were processed with a matrix provided by the manufacturer. Data from the radiometer 06 were processed with a matrix calculated by the PMOD-WRC during the COST Action 726, in 2006. A fixed correction factor was used with instruments 07 and $09-10$. The former was calibrated with reference to the QASUME travelling standard during a spectroradiometer comparison in 2008. Radiometers 09-10 were calibrated by the manufacturer in 2010. Finally, instrument 08 used the algorithm developed by Bodhaine et al. (1998) and was calibrated with reference to Brewer \#123 (which is in turn traceable to NIST) belonging to the Italian National Agency for new technologies, energy and sustainable economic development (ENEA).

\subsection{Narrowband radiometers}

The narrow-band filter radiometer UV-RAD (id 12) has been designed and developed at the Institute of Atmospheric Sciences and Climate (ISAC) of the Italian National Research Council (CNR), as part of a cooperative program with ENEA. The UV-RAD is able to measure the solar UV irradiance in seven channels centered at $300,306,310,314$, 325,338 and $364 \mathrm{~nm}$ wavelengths with FWHM varying from 0.7 to $1 \mathrm{~nm}$. The overall scan of the channels takes about $90 \mathrm{~s}$. Further details about the instrument are given by Petkov et al. (2006). The UV-RAD radiometer was calibrated by 
comparison against two Bentham spectroradiometers traceable to international standards: a first campaign was organized in Alomar (Norway) in 2004; a second comparison was performed in Saint-Christophe (Italy) in 2006. The measurements recorded by UV-RAD allow the retrieval of column ozone applying the method developed by Stamnes et al. (1991). To reconstruct the UV spectral irradiance at the ground, the atmospheric transmittance was assessed at the measured wavelengths and the spectrum was evaluated through a radiative transfer model at the time of observation, using the retrieved total ozone as an input.

The F-RAD radiometer (id 13) has been developed by ENEA. It operates on 13 wavelengths from about 281 to $378 \mathrm{~nm}$ which are selected by as many filters characterized by a FWHM from 0.5 to $1.3 \mathrm{~nm}$. Each filter is manufactured by the Optical Components Group of ENEA using ion-assisted vapour-phase evaporation. This technique ensures an excellent stability in time. The radiometer is equipped with a GPS receiver for time synchronization and is temperature-stabilized to $\pm 0.5^{\circ} \mathrm{C}$ using a Peltier cell. The overall scan of the channels takes about $1 \mathrm{~min}$. The calibration of F-RAD was performed in two steps. At first, a field calibration system developed by NIST and NOAA (Early et al., 1998) which uses several $1000 \mathrm{~W}$ FEL lamps traceable to NIST was used. Then, the F-RAD measurements were compared with simultaneous co-located spectra from Brewer \#123 obtained during three months at the ENEA observatory in the Lampedusa island (Southern Italy). Brewer \#123 is regularly calibrated with the field calibrator and was characterized for its cosine response (Bais et al., 2005) and slit function. The spectra used in the comparison were reconstructed from narrowband irradiances using the Tropospheric Ultraviolet and Visible (TUV) radiation model (Madronich, 1993).

\subsection{Radiative transfer calculations}

A radiative transfer model, the libRadtran package (Mayer and Kylling, 2005), was used in the campaign for comparing different kinds of data as explained in Sect. 4 and as a further quality control. Table 5 summarizes the data set entered as input to the model.

The solar spectrum was set to the recommended value following the model documentation (Atlas-3, shifted to air wavelengths). Default summer atmospheric profiles were used. Pseudo-spherical discrete-ordinate method (DISORT) with double precision was chosen as the solver, since a simple plane-parallel DISORT solver showed relevant deviations from the reference instrument even for low zenith angles. The effective ground albedo was set to $3 \%$ (Degünther et al., 1998). Rural aerosol properties, background stratospheric aerosols and the default Shettle aerosol profile were given as inputs to the model. Since independent measurements of the aerosol single scattering albedo (SSA) were not available during the campaign, the SSA value was chosen in order
Table 5. Input parameters to the radiative transfer model.

\begin{tabular}{|c|c|}
\hline Parameter & Value \\
\hline Solar spectrum & Atlas-3 (shifted to air wavelengths) \\
\hline Atmosphere & Standard midlatitude summer \\
\hline Aerosol properties & $\begin{array}{l}\text { Shettle profile, } \\
\text { rural type, } \\
\text { background stratospheric }\end{array}$ \\
\hline SSA & Default reduced by $10 \%$ \\
\hline Ångström parameters & Brewer measurements \\
\hline Ozone cross sections & Molina\&Molina 1986 \\
\hline Number of streams & 12 \\
\hline Altitude & $570 \mathrm{~m}$ a.s.l. \\
\hline Total ozone & Brewer measurements \\
\hline $\begin{array}{l}\text { Effective ground } \\
\text { albedo }\end{array}$ & $3 \%$ \\
\hline Local pressure & $950 \mathrm{hPa}$ \\
\hline Solver & Pseudospherical disort (sdisort) \\
\hline Convolution & Triangular slit function (FWHM $1 \mathrm{~nm}$ ) \\
\hline
\end{tabular}

to best reproduce several spectral measurements recorded with Bentham 5541 during clear-sky days in summers 2008 to 2010 at Saint-Christophe (wintertime measurements were not considered because of changes of effective ground albedo due to the snow) as explained by Ialongo et al. (2010). Therefore, the single scattering albedo (SSA) was reduced by $10 \%$ relative to the default model value (i.e. 0.90 to 0.95 depending on the wavelength). Similarly, the Molina\&Molina ozone cross sections were chosen because of their agreement with the Bentham spectral measurements in the range $295 \div 330 \mathrm{~nm}$.

The Ångström coefficients were retrieved from the Brewer measurements in the UV and visible range, as explained in Sect. 2.2. Local atmospheric pressure was taken equal to a constant value of $950 \mathrm{hPa}$, since the measured pressure during the campaign was stable within $\pm 5 \mathrm{hPa}$ (the error introduced by using a constant value is less than $0.4 \%$ at $290 \mathrm{~nm}$ and even lower at higher wavelengths). The diffuse irradiance was scaled to $95 \%$ accounting for the mountain horizon under the hypothesis of isotropic diffuse radiation, as explained by Diémoz and Mayer (2007). This cosine-weighted fraction was calculated from both theodolite measurements and a digital elevation model.

The simulated spectra were then treated similarly to the instrumental data (id 14 was assigned to the model) and compared to the reference.

\section{Campaign overview}

\subsection{Campaign protocol}

Every participating agency was asked to send a calibrated radiometer to the organizers or, in case of complex instrumentation, to assist with a specialized operator. The campaign 
began on 8 June (day of year 159) and ended on 24 June (day of year 175), comprising days across the summer solstice, thus allowing measurements at a large range of solar elevations. Synchronous measurements of solar irradiance were collected for the whole time period. Every instrument (or computer connected to an instrument) was synchronized to the same reference through the Internet Network Time Protocol or a GPS signal. The quartz domes of the radiometers were cleaned and the horizontal leveling was checked every morning before sunrise.

At the end of the campaign, the raw series (e.g. the series of the recorded voltages, for the broadband radiometers) were individually reprocessed by the respective operators using the same algorithm and calibration data usually employed by each agency. The data were then sent to ARPA Valle d'Aosta for the comparison in terms of the global solar UV Index (Vanicek et al., 1999) or UV-A irradiance.

\subsection{Site description}

The site of Saint-Christophe $\left(45.8^{\circ} \mathrm{N}, 7.4^{\circ} \mathrm{E}, 570 \mathrm{~m}\right.$ a.s.1. $)$ is located in Northwestern Italy, in the Alpine region. It was chosen because of the presence of state-of-the-art instruments necessary for the comparison: a spectroradiometer traceable to international standards and a calibrated Brewer spectrophotometer. The site is also characterized by low pollution levels. Even though Saint-Christophe lies in a valley bottom, the horizon is free enough to allow meaningful solar measurements. Figure 2 shows the horizon at the intercomparison site, together with the daily course of the sun position for 8 June 2010. Anyway, data recorded when the sun was behind the mountains were removed from the analysis. The sunrise was at about 05:00 UT and the sunset at about 18:00 UT during the campaign. The minimum solar zenith angle was $22.3^{\circ}$ corresponding to the summer solstice.

\subsection{Atmospheric conditions}

Cloudy sky accompanied the first part of the campaign. Some showers occurred in the period from 9 to 17 June. Data recorded under rainy conditions were removed from the analysis. The last four days (21-24 June) were almost clear and the maximum UV Index was about 8 , which is a typical value for the site of Saint-Christophe in summer.

\section{Methods}

Since the instruments to be compared against the reference belong to very different classes (spectral, narrow- and broadband radiometers), a common procedure of analysis to be applied to all instruments is not suitable. Most notably, since the sampling frequencies of the instruments are considerably different, a common approach for all instruments involved in the campaign should be based on the adoption of an identical time resolution (i.e. downscaling all data to the lowest

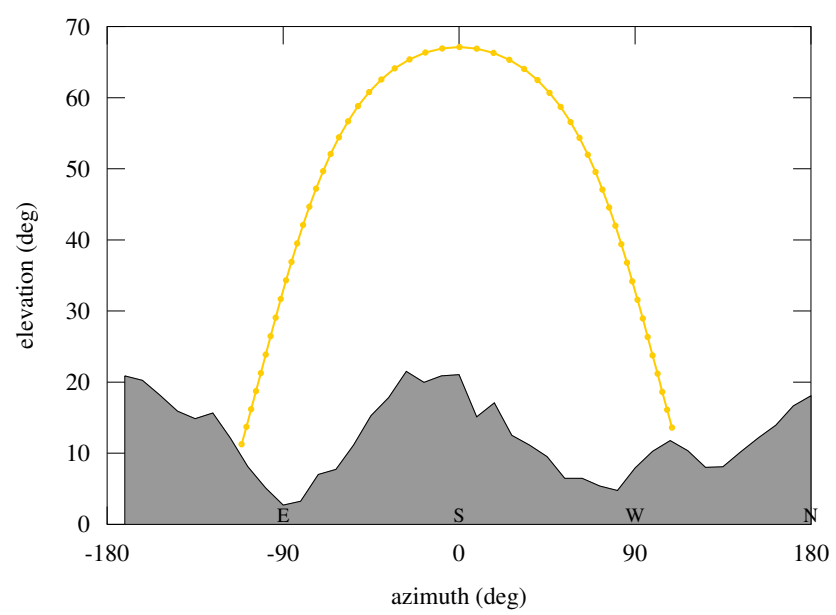

Fig. 2. Horizon and sun elevation at Saint-Christophe. The sun trajectory for 8 June is drawn from 05:00 UT to 17:45 UT. Circles are plotted every $15 \mathrm{~min}$.

resolution among the participating instruments) which is inappropriate and can lead to ambiguous results. Indeed, the deviations to the reference would increase due to the temporal interpolation, making arduous to discriminate the dispersion originating from other factors and the dispersion from the interpolation itself.

A reliable and rigorous analysis is essential to correctly compare the processing procedures used by each participating institution, which is one of the purposes of the campaign. Therefore, an appropriate algorithm must be employed for each class of instruments for comparing the UV data recorded by the various instruments against the reference and reducing the dispersion originating from the temporal interpolation. The methods are described below.

\subsection{Analog broadband radiometers}

The weighted and integrated irradiance measured with a broadband radiometer can be expressed in the following general form, provided that appropriate angular and spectral corrections are applied to the data:

$I_{\mathrm{CIE}}(t)=\int I(\lambda, t) \operatorname{CIE}(\lambda) d \lambda$

$\operatorname{CIE}(\lambda)$ being a standardized action spectrum (the erythemal spectrum (CIE, 1998) or the UV-A unitary function between 315 and $400 \mathrm{~nm}$ and zero below $315 \mathrm{~nm}$; CIE, 1999) and $I(\lambda, t)$ the solar spectral irradiance at the ground at time $t$. Unfortunately, as already stated in the previous sections, we are not able to measure the instantaneous value of $I(\lambda, t)$, since a full scan of the spectroradiometer takes about $3 \mathrm{~min}$. Hence, it was decided to downscale the temporal resolution of the broadband data to optimize the comparison with the spectral measurements and an appropriate algorithm was developed. 
The downscaled irradiance from broadband radiometers was calculated as

$$
I_{d s}=\frac{\int I_{\mathrm{BB}}(t(\lambda)) I_{\mathrm{SP}}^{0}(\lambda, t(\lambda)) \mathrm{CIE}(\lambda) d \lambda}{\int I_{\mathrm{SP}}^{0}(\lambda, t(\lambda)) \operatorname{CIE}(\lambda) d \lambda}
$$

where $I_{\mathrm{BB}}(t(\lambda))$ are the CIE-weighted and cosine-corrected broadband irradiances reprocessed by the operators and $I_{\mathrm{SP}}^{0}(\lambda, t(\lambda))$ is the clear-sky irradiance simulated by the radiative transfer code at the time at which the reference instrument is measuring the wavelength $\lambda$.

We also assume that clouds act as a grey filter, i.e. the spectral transmittance of the cloud at all wavelengths can be approximated by the transmittance integrated over a wavelength band (e.g. UV-A or the erythemal range). Marking the modeled clear-sky irradiance over the spectral band of interest with $I_{\mathrm{BB}}^{0}(t)$, i.e.

$I_{\mathrm{BB}}^{0}(t)=\int I_{\mathrm{SP}}^{0}(\lambda, t) \operatorname{CIE}(\lambda) d \lambda$

we obtain:

$\frac{I_{\mathrm{BB}}(t)}{I_{\mathrm{BB}}^{0}(t)} \approx \frac{I_{\mathrm{SP}}(\lambda, t)}{I_{\mathrm{SP}}^{0}(\lambda, t)} \quad \forall \lambda$

As previously stated, a spectral scan of the reference instrument takes about $3 \mathrm{~min}$. During this time, the variation of $I_{\mathrm{BB}}^{0}(t)$ depends uniquely on the change of the solar zenith angle and can be considered negligible with respect to the fluctuations of the measured irradiance, $I_{\mathrm{BB}}(t)$, which is induced by the transit of broken clouds. Based on radiative transfer calculations, the error in considering $I_{\mathrm{BB}}^{0}(t)$ as a constant is estimated to be lower than $1 \%$. Thus, we obtain:

$I_{d s} \approx \int I_{\mathrm{SP}}(\lambda, t(\lambda)) \operatorname{CIE}(\lambda) d \lambda$

The right-hand term is the CIE-weighted irradiance value as measured by the reference instrument in a scan time.

Thus, the comparison for broadband radiometers consisted in analyzing the series of ratios between the downscaled broadband irradiances in Eq. (2) and the convoluted reference spectra in Eq. (5). The implementation of the algorithm used look-up tables (previously calculated with libRadtran) to quickly obtain the appropriate modeled irradiance.

The timestamp relative to the downscaled irradiance was calculated as

$t_{d s}=\frac{\int t(\lambda) \operatorname{CIE}(\lambda) I_{\mathrm{SP}}^{0}(\lambda, t(\lambda)) d \lambda}{\int \operatorname{CIE}(\lambda) I_{\mathrm{SP}}^{0}(\lambda, t(\lambda)) d \lambda}$

The results of the improved algorithm are presented in Sect. 5.
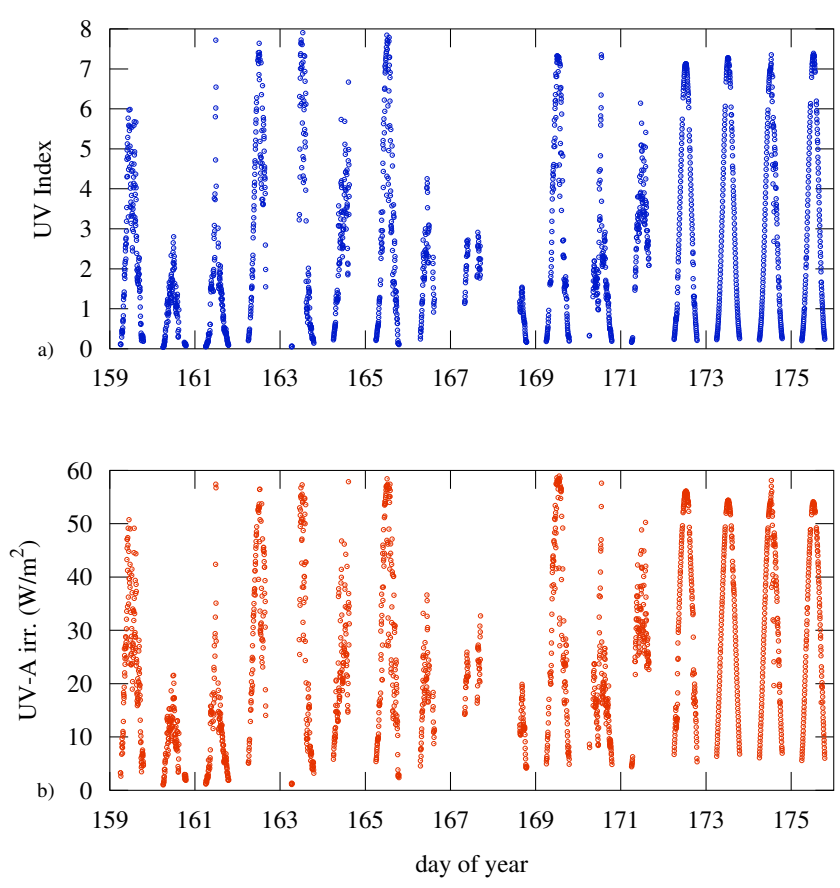

Fig. 3. Time series of Bentham measurements: (a) global solar UV Index and (b) UV-A irradiance. Data for rainy periods, before sunrise, after sunset, during calibration of the reference and dome cleaning were not included in the graph.

\subsection{Digital broadband radiometers, narrowband and spectral instruments}

The previous algorithm was not applicable to digital broadband radiometers (id 09-10), narrowband (id 12-13) and spectral instruments (id 11), since measurements were taken at a too low frequency. Instead, a simple interpolation was used to compare data at the right time. The spectra obtained by the reference, the Brewer and the narrowband radiometers were weighted and integrated and a timestamp was assigned to the obtained values following Eq. (6). Timestamp of the digital radiometers was set to the middle of the sampling time. The user and the reference series were then appropriately interpolated (the series sampled at the highest frequency was interpolated to the other) and the ratios between the series were calculated. Care was taken to avoid interpolation in case of too large time intervals ( 1 min for narrowband radiometers and $5 \mathrm{~min}$ for the Brewer).

The spectral irradiances obtained with narrowband radiometers and the Brewer were also analysed in detail to assess the behaviour of the instruments at different wavelengths. However, spectral ratios are not presented here, since beyond the scope of this paper. 


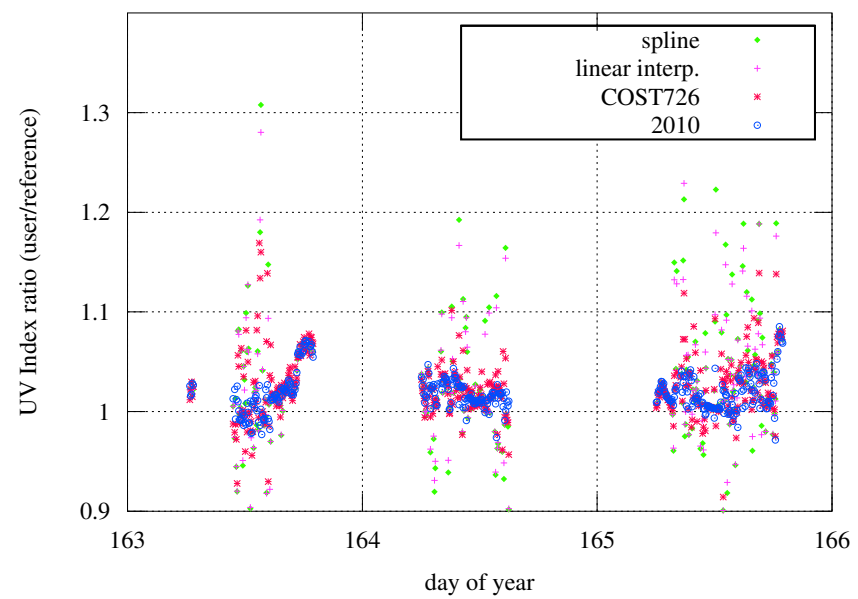

Fig. 4. Comparison of several methods to downscale the broadband data. The graph shows the ratio of the broadband irradiance measured with instrument 01 and the reference during three cloudy days. Cubic spline interpolation is represented with green diamonds, simple linear interpolation with pink crosses, the COST Action 726 algorithm with red asterisks and the algorithm used in this study with blue circles.

\section{Results and discussion}

Figure 3 shows the time series of the measurements recorded by the Bentham spectroradiometer, in terms of global solar UV Index and UV-A irradiance. Cloudy days are clearly visible in the first part of the campaign (days of year 159 to 171).

The ratios between the measurements made by each instrument and the reference were then analyzed. Figure 4 presents a comparison of several methods to downscale the data from broadband radiometers during three cloudy days. The aim is to draw attention to the risk of an indiscriminate use of time interpolations. First, the ratios derived by interpolating the broadband values to the most representative time of the reference spectra using a cubic spline and a simple linear interpolation are shown. Cubic splines are chosen since they were applied to depict the results of the COST726 campaign (G. Hülsen, personal communication, 2010). As can be seen from the figure, the results obtained in cloudy conditions are not optimal and present some fictitious fluctuations. The linear interpolation gives results similar to the cubic spline. The new algorithm developed in this study is less influenced by clouds than the two interpolations and the COST Action 726 algorithm.

We decided to use the median and the interquartile range (IQR) to describe the statistical distributions of the ratios, which are not normally distributed and show many outliers. The former is a measure of the central tendency of a sample and the latter is a measure of dispersion. Boxplots (Figs. 5 and 6) summarize the results during clear sky days (days 172 to 175$)$.

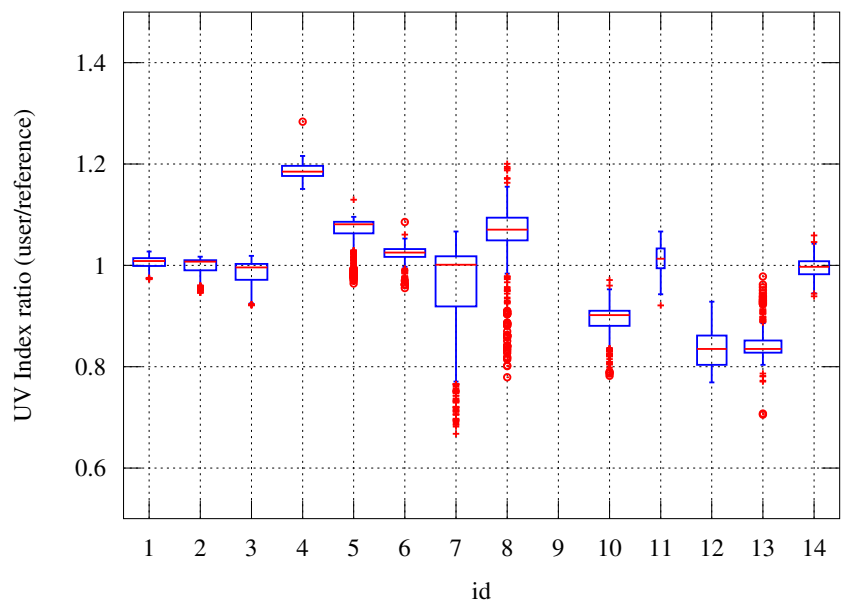

Fig. 5. Boxplot of UV Index ratios between each instrument and the reference, calculated under clear sky conditions. The top and the bottom of the boxes represent respectively the upper and the lower quartiles. The line inside every box depicts the median. The whiskers show minimum and maximum values except the outliers, which are drawn as cross (between 1.5 and 3 times the IQR) and circles (beyond 3 times the IQR). Instrument id 09 does not measure the UV Index.

\subsection{Relative deviations from the reference under clear sky conditions}

We first analyze the median values of the ratios between the radiometers and the reference (Figs. 5 and 6). Remarkable differences may be noticed among the instruments: the differences relative to the reference spectroradiometer range from $-16 \%$ (instruments 12 and 13) up to $19 \%$ (instrument 4) for the UV Index series. It is interesting to observe that UV-A data from double-band radiometers show similar patterns, denoting an internal consistency in all instruments. It has to be noticed that even radiometers recently calibrated by the respective manufacturers present significant deviations (instruments 04, 05, 09, 10). Some radiometers, along with the reference, share the same calibration standard (PMODWRC/QASUME) and this is clearly depicted in the graphs: instruments $01,02,03,06,07,11$ show median ratios of about 1 . In particular, it must be emphasized that radiometers 01, 02 and 03 and the Brewer (id 11) were all calibrated against the Bentham as described in Sect. 2.4. Since the IQRs of those radiometers are very low (ranging from 1.4 to $3 \%$ ), this exercise also provides information on the radiometers stability and the reliability of the angular corrections.

The values obtained with radiometer 08 are consistent with the results of previous comparison between the ENEA instrumentation and QASUME (the former overestimates QASUME by about $5 \%$ ) (Gröbner et al., 2006). The large discrepancies of the UV-RAD (id 12) may be ascribed to deterioration of the internal components (e.g. filters, O-ring) and drift in calibration. Narrowband radiometer 13 was 


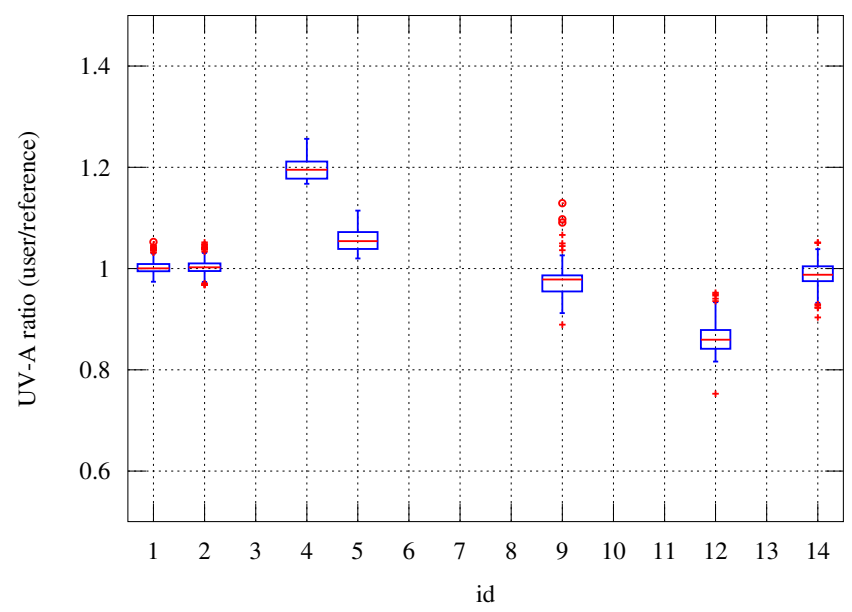

Fig. 6. Boxplot of UV-A irradiance ratios between each instrument and the reference, calculated under clear sky conditions. Only instruments measuring UV-A irradiance can be shown in the graph.

thoroughly examined after the campaign and a sealing defect was discovered which let humidity and dust enter the instrument (thus decreasing its sensitivity). Finally, although the radiative model (id 14) was configured with few basic parameters, the results are rather satisfying: the difference relative to the reference is $-0.3 \%$ for the UV Index and $-1.2 \%$ for the UV-A irradiance.

\subsection{Daily variability in clear sky conditions}

Figures 5 and 6 clearly show that the series of measurements of every instrument have a different IQR during clear sky days. Even though the angular response of the radiometers was not measured during the campaign, most of the total variability for clear sky conditions, as we will see later, is clearly ascribable to the daily (not day-to-day) variability, since the ratios distinctly depend on the solar elevation. To investigate the angular dependence, the ratios were plotted against the solar zenith angle (Figs. 7 and 8) for the morning and the afternoon separately for clear sky days.

The ratios from the series processed with state-of-the-art algorithms (i.e. matrix of coefficients) are characterized by lower daily variability (id 01 to 06 ). On the contrary, radiometer 07 , whose median was close to unity, shows very clear angular dependence and the largest IQR for clear sky $(10 \%)$. Indeed, since a single constant factor has been used for the conversion from the electric signal to the irradiance, angular and spectral errors are not considered. This is also the case of radiometers 09 and 10, which, however, exhibit a better cosine response than 07 . Similarly, the ratios for radiometer 08 show a particular shape. The corrections applied to that radiometer use an empirical function obtained by comparison with Brewer \#123. It must be emphasized that the ratio is reasonably constant at solar zenith angles lower than $70^{\circ}$ and most of the deviations appearing in Fig. 5 are due to measurements at larger solar zenith angles. An incorrect determination of Brewer \#123 cosine response at large incidence angles or of the spectral sensitivity of the broadband radiometer could be responsible for the strange behaviour. Further investigations are being carried out. The daily variability of the Brewer spectrophotometer (id 11) is within the uncertainty of the radiative model used for the correction and the instrumental uncertainty. The angular dependence of the narrowband radiometer 13 is pronounced only for zenith angles above $60^{\circ}$. This behaviour will be investigated in detail by the owner agency.

The daily variability of the model is comparable to the uncertainty of other instruments. This shows that both model and reference instrument are consistent. The daily variability can arise from the hypothesis of isotropy. Actually, since the diffuse radiation is not perfectly isotropic, the factor accounting for the horizon may be different from $95 \%$ and may even vary depending on the solar zenith angle, cloud cover, aerosol load, etc. However, the induced error is likely much lower than the uncertainty resulting from the unknown input model parameters.

\subsection{Morning/afternoon asymmetry}

Several instruments present an asymmetry between the morning and the afternoon ratios. For some of them (id 01, $04,06,12)$ the difference between the morning and afternoon ratios is very small (less than about $2 \%$ ) and may be ascribable to the deterioration or misalignment of the leveling bubble (id 01), to a slight azimuthal dependence (already noticed e.g. for radiometer 06 during the COST Action 726 campaign) as well as to the effect of the internal temperature or humidity.

The morning/afternoon change is slightly higher for radiometer 05 , about $3 \%$. The difference is clearly visible also in the unprocessed series of voltages, so that an error relating to the processing can be easily excluded. An asymmetry of about $4 \%$ is also present in the Brewer ratios. However, the variation is not explainable neither by an azimuthal dependency (the Brewer turns on its axis during the day and follows the solar azimuth) nor by a leveling problem (the spectral ratios, not presented here, reveal that the Brewer asymmetry is higher for the lowest wavelengths). Unaccounted temperature and humidity effects may be responsible for this behaviour.

\subsection{Effect of clouds}

The effect of clouds on the ratios can be examined taking into account the series of measurements recorded in the whole campaign period (days 159 to 175), in both cloudy and clear days (Figs. 9 and 10). While median values do not change appreciably, the scatter of the ratios for each instrument and, in particular, the difference between the maximum and minimum values (i.e. the distance between the whiskers in the 

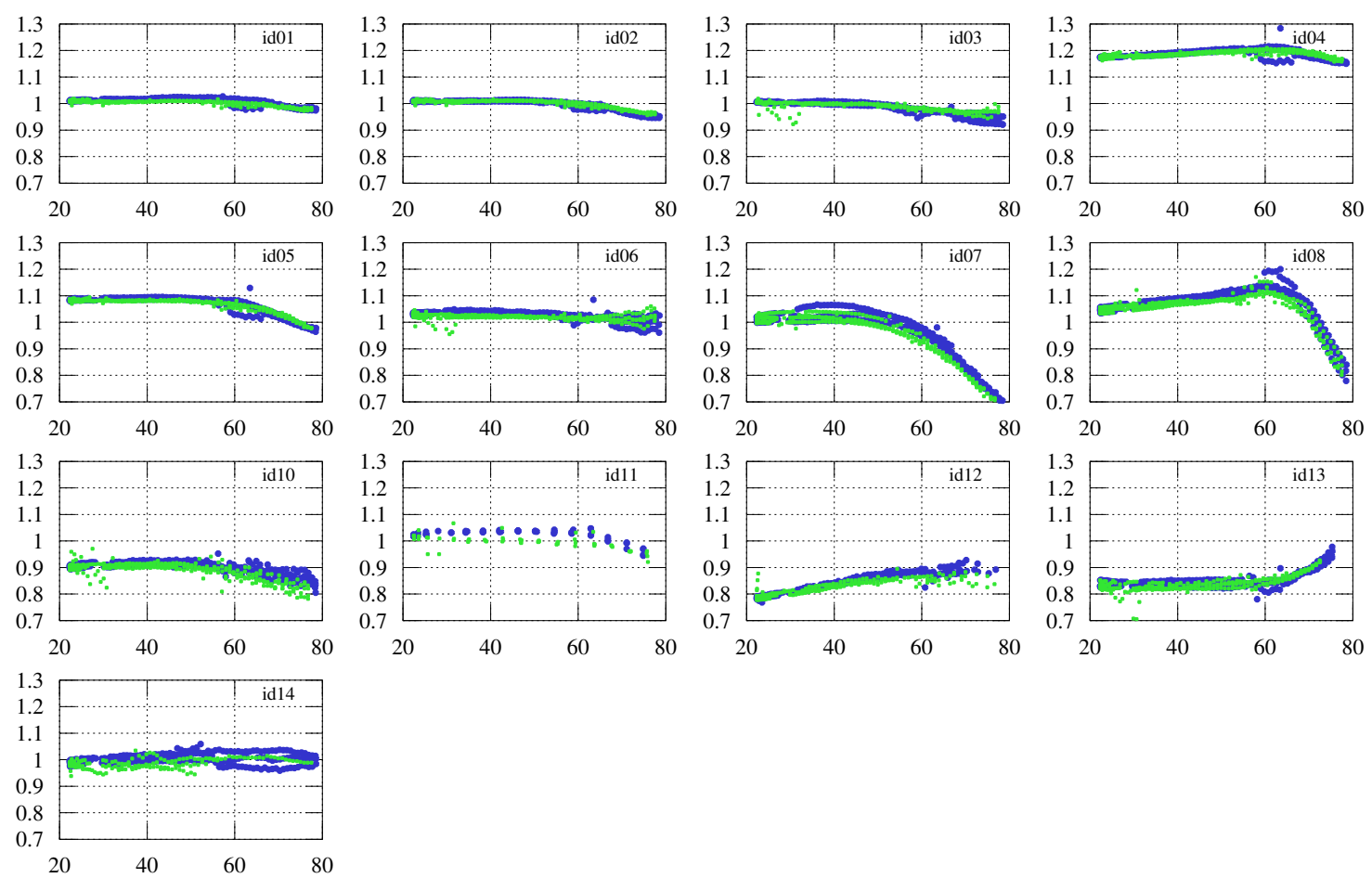

Fig. 7. Ratios between clear-sky UV Index measurements with user instruments and the reference (vertical axis) against the solar zenith angle (horizontal axis). Morning (blue) and afternoon (green) measurements are plotted separately.
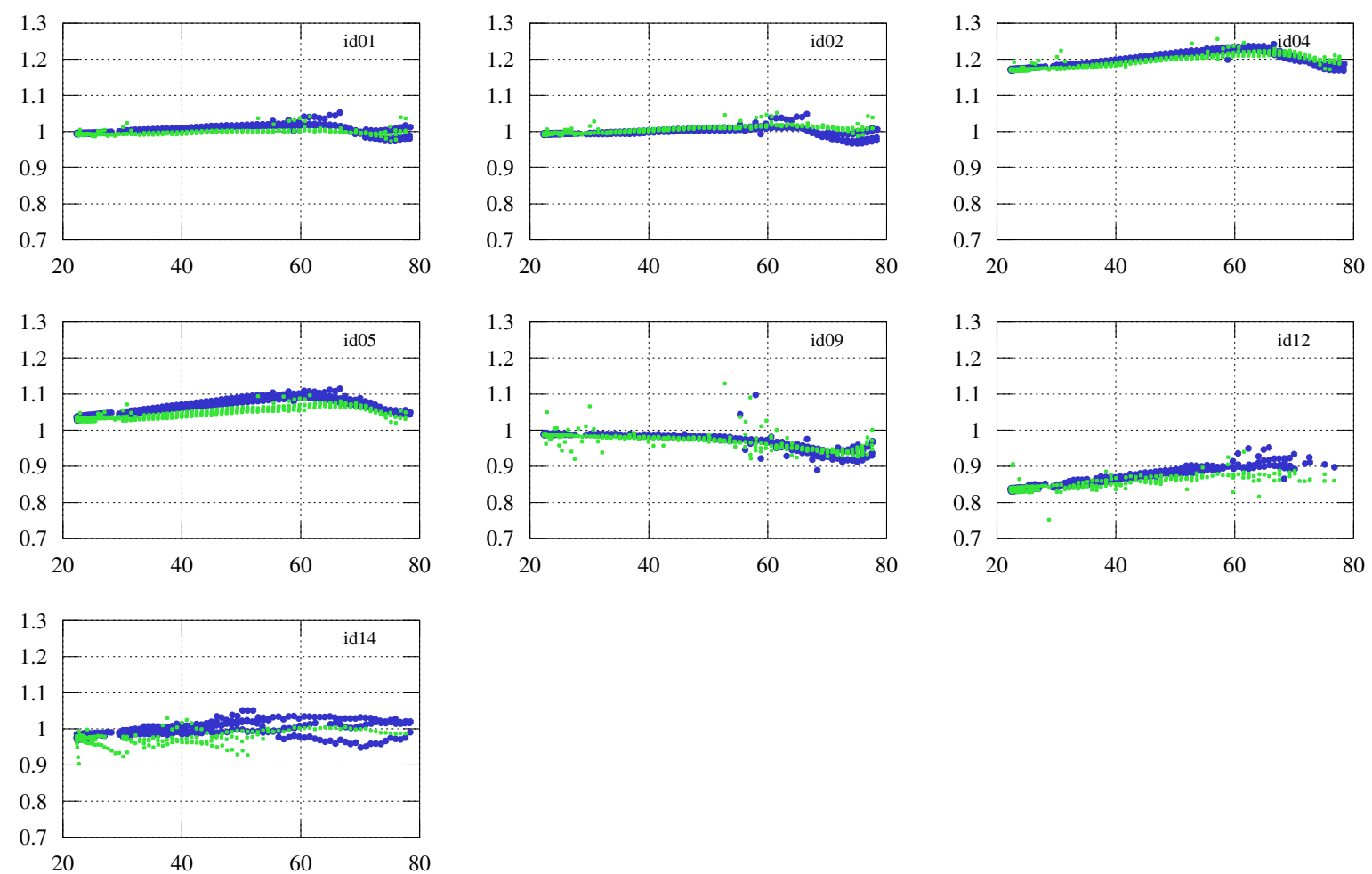

Fig. 8. Ratios between clear-sky UV-A irradiance measurements with user instruments and the reference (vertical axis) against the solar zenith angle (horizontal axis). Morning (blue) and afternoon (green) measurements are plotted separately. 


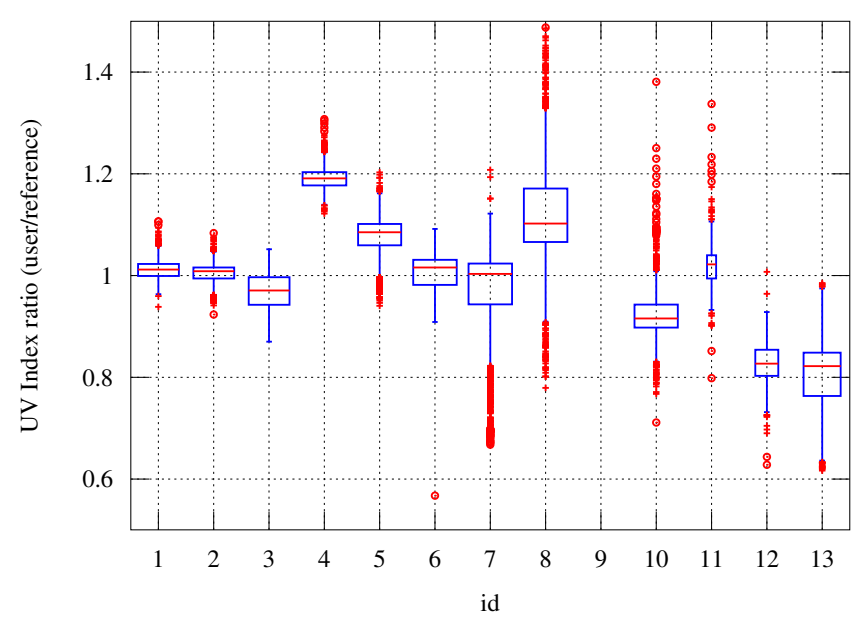

Fig. 9. Boxplot of UV Index ratios between each instrument and the reference, calculated under all sky conditions (both cloudy and clear days). The clear-sky simulations (id 14) were not considered in the analysis.

boxplots), increase noticeably and in many cases exceeds $\pm 10 \%$. This is to ascribe to many factors, depending on the instruments.

First, the analysis procedure which was applied to the ana$\log$ broadband data allows to reduce the effect of time interpolations on the ratios. The dominant factor modulating the ratios must therefore be the influence of clouds on the cosine corrections, which were calculated under the hypothesis of clear sky conditions. This latter approach is, of course, simplistic, but it is adopted by most of the broadband operators worldwide. Also, more rigorous corrections would require cloud cover data which are not always available. For instance, a complete spectral correction in cloudy cases would strongly depend on both cloud cover and cloud optical thickness (Mateos et al., 2011). A simpler correction is possible in the borderline case of overcast sky in presence of thick clouds, taking into account only the fraction of scattered radiation while neglecting the direct beam. Nevertheless, this diffuse correction would require a complete radiometer characterization (angular and spectral responses), which was not available for all radiometers. However, the increase of the IQRs for analog broadband radiometers during cloudy conditions with respect to clear-sky conditions is a good estimate of the error on the cosine correction originating from the clear-sky simplification. It is interesting to notice that radiometers with a good cosine response (i.e. with a smooth matrix), for example id 01, 02, 04 and 05 , show slightly better performances compared to the others, e.g. id 03 and 06. In the case of instruments with coarser time resolutions (e.g. 09 to 11 and, to a lesser degree, 12 and 13), time interpolations between measurements may produce large deviations. However, a more in-depth analysis of cloud effects on the cosine corrections for these instruments is beyond the purpose of this paper and may be studied in a future work.

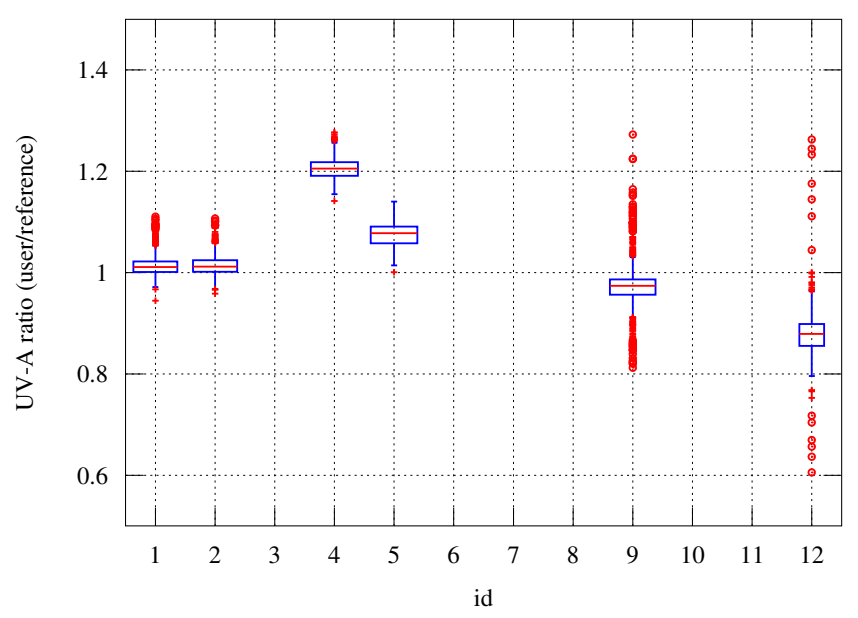

Fig. 10. Boxplot of UV-A irradiance ratios between each instrument and the reference, calculated under all sky conditions (both cloudy and clear days).

Finally, it is interesting to notice that the error is amplified by the processing algorithms applied on radiometers 07 and 08 . In those cases, the full range of the ratios may exceed $\pm 20 \%$ or even $\pm 30 \%$.

\subsection{Overall performances of the radiometers and recommendations}

Even within the uncertainty of the reference instrument, some inferences about the general performances of the radiometers can be drawn and some recommendations may be consequently formulated.

Figure 11 shows both the relative deviation from the reference during clear sky days and the IQR distance. Only results from the UV Index comparison are represented (UV-A irradiances have a similar behaviour and are omitted). Angular and spectral corrections employed by the operators are also reported in parentheses next to the instrument id. Some groups of instruments, which show similar performances, can be identified.

One of the most striking features of the graph is the importance of the traceability. Indeed, most of the instruments traceable to NTP (directly through QASUME or, with a further step, through Bentham 5541), with the only exception of instrument 12 , show very low deviations with respect to the reference (blue markers). This points out the importance of a common and reliable reference scale and the effectiveness of a travelling standard such as QASUME. It is interesting to notice that the relative deviations from the reference among this group do not appreciably depend on the age of the last calibration. Broadband radiometers such as id 06 and 07 are stable, even after some years of operation after their last calibration. However, sudden changes may occur and calibrations on a more frequent basis are recommended. 


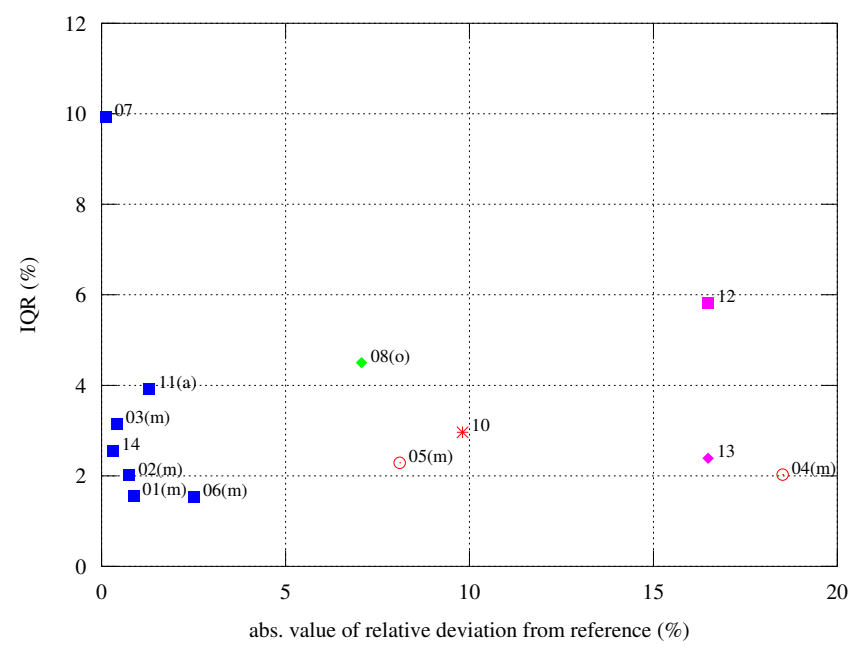

Fig. 11. Summary of the overall performances of the radiometers during clear sky days. Only results relative to the UV Index are shown. The horizontal axis represents the absolute value of the relative difference between the instruments and the reference (median of the ratios of previous graphs, minus unity). The vertical axis represents the IQR distance.The shape of the markers refers to the traceability: NTP through QASUME or Bentham 5541 (squares), NIST through Kipp\&Zonen facility (circles), NIST through Yankee Env. Systems facility (asterisk), NIST through ENEA Brewer \#123 (diamonds). The letters beside the id numbers mark the correction methods to the measurements: spectral-angular matrix (m), only angular correction (a), other corrections (o) and fixed coefficient or no correction at all (no markers). Colours are used to identify instruments with similar characteristics (see text).

Instruments which were calibrated by their respective manufacturers few months before the campaign may be included in a second group (red colour). This group is characterized by moderate to large deviations relative to the reference. Moreover, consistency among instruments calibrated by the same facility (e.g. id 05 and 04) is weirdly low. Furthermore, instrument 04 was recalibrated at the same laboratory after the comparison and is now only about $4 \%$ higher than the reference. Such large discrepancies remain unexplained.

Finally, a third group including two radiometers designed and built by ENEA and CNR-ISAC is highlighted (violet colour). Large relative deviations with respect to the reference are found. The intercomparison helped in identifying technical problems such as deterioration of internal components and drifts in calibrations. Thus, particular attention should be taken when operating with home-made radiometers and comparisons with reference instruments should be scheduled very often.

A further classification may be done according to the processing procedures and correction algorithms. Generally, radiometers processed using a matrix (which takes into account both spectral and angular corrections) show a lower IQR. On the contrary, other kinds of corrections, such that employed for radiometer 08 , are not so effective. When a fixed calibration factor is used, the IQR may be even worse, as in the case of radiometer 07 . Even though low daily variations may be obtained (as with instrument 10) with a fixed calibration factor, possibly because of a good cosine response, both spectral and angular corrections should be always employed.

Generally speaking, performances of the radiometers, especially of those with the highest deviations or IQRs, could be greatly improved by using state-of-the-art correction algorithm and planning frequent intercomparison for monitoring the instrumental stability.

\section{Summary and conclusions}

This study was stimulated by the need to assess the accuracy of the Italian UV measurements in order to plan a future national network which will be able to guarantee reliable and homogenized data. 14 instruments belonging to 8 different agencies participated to the campaign. Most radiometers (11 of 13) are commercialized worldwide. The campaign also represented a chance of comparing several data processing algorithms employed by the participating institutions.

The comparison lasted in total 17 days characterized by cloudy and clear skies. About 3000 irradiance spectra and 140000 samples were collected respectively for each spectral/narrowband and broadband instrument. The data obtained by the tested instruments were compared to a wellcalibrated Bentham double monochromator spectroradiometer. The results were presented in terms of ratios between the user instruments and the reference. An optimized algorithm was specially developed to compare high-frequency broadband measurements with reference spectra. Average deviations ranging from $-16 \%$ to $+19 \%$ and interquartile ranges up to $10 \%$ even for clear sky days were discovered and discussed. Three radiometers, which had been calibrated few months before the campaign by their respective manufacturers, showed significant deviations to the reference. The average deviations and daily variations were very large compared to the uncertainty of state-of-the-art instruments. Moreover, they were greater than the expectations of the respective operators. However, out of the 13 instruments which were compared to the reference spectroradiometer, eight showed median and interquartile ratios which were within $\pm 10 \%$ of the reference; five were within $\pm 5 \%$. The ratios from the libRadtran radiative model, which was configured with few basic parameters, were satisfying and within few percents of the reference under clear sky conditions. The intercomparison also allowed the identification of a sealing defect of one of the narrowband radiometers and possible problems in the cosine correction of some instruments.

Consistent efforts to improve the calibration of the instruments and the processing algorithms are essential and should be made before deciding to set up a national network. The 
results highlight the importance of intercomparisons, which could be repeated every few years, also to assess the effects of the forthcoming corrective actions.

All data from the intercomparison are freely downloadable from www.uv-index.it for further research purposes.

Acknowledgements. The authors would like to thank S. Saudino and S. Martorina from ARPA Piemonte, F. Sabatini from CNRIBIMET/LaMMa, I. Di Sarcina and F. Menchini from ENEA, V. Lanorte from ARPAB for their valuable help with the campaign, the calibration and data processing of the instruments. The authors also acknowledge the anonymous reviewers for their constructive suggestions.

Edited by: K. Strong

\section{References}

Bais, A., Topaloglou, C., Kazadtzis, S., Blumthaler, M., Schreder, J., Schmalwieser, A., Henriques, D., and Janouch, M.: Report of the LAP/COST/WMO Intercomparison of Erythemal Radiometers, Thessaloniki, Greece, Tech. rep., World Meteorological Organization - Global Atmosphere Watch, 1-54, 2000.

Bais, A. F., Kazadzis, S., Garane, K., Kouremeti, N., Gröbner, J., Blumthaler, M., Seckmeyer, G., Webb, A. R., Koskela, T., Görts, P., and Schreder, J.: Portable device for characterizing the angular response of UV spectroradiometers, Appl. Optics, 44, 71367143, 2005.

Bernhard, G. and Seckmeyer, G.: Uncertainty of measurements of spectral solar UV irradiance, J. Geophys. Res., 104, 1432114346, 1999.

BIPM, IEC, IFCC, ILAC, ISO, IUPAC, IUPAP and OIML: Evaluation of Measurement Data-Guide to the Expression of Uncertainty in Measurement GUM 1995 with minor corrections, Joint Committee for Guides in Metrology, available at: http://www.bipm.org/documents/jcgm/JCGM_100_2008_E.pdf (last access: 29 August 2011), 2008.

Bodhaine, B. A., Dutton, E. G., McKenzie, R. L., and Johnston, P. V.: Calibrating Broadband UV Instruments: Ozone and Solar Zenith Angle Dependence, J. Atmos. Ocean. Tech., 15, 916-926, 1998.

Casale, G. R., Meloni, D., Miano, S., Palmieri, S., Siani, A. M., and Cappellani, F.: Solar UV-B irradiance and total ozone in Italy: Fluctuations and trends, J. Geophys. Res., 105, 48954902, 2000.

Cheymol, A. and De Backer, H.: Retrieval of the aerosol optical depth in the UV-B at Uccle from Brewer ozone measurements over a long time period 1984-2002, J. Geophys. Res., 108, 48004809, 2003.

CIE: Erythema reference action spectrum and standard erythema dose, Tech. rep., Commission Internationale de l'Éclairage, 1998.

CIE: 134/1 TC 6-26 report: Standardization of the Terms UVA1, UV-A2 and UV-B, Tech. rep., Commission Internationale de l'Éclairage, 1999.

Degünther, M., Meerkötter, R., Albold, A., and Seckmeyer, G.: Case study on the influence of inhomogeneous surface albedo on UV irradiance, J. Geophys. Res., 25(19), 3587-3590, 1998.
Di Menno, I., L. Moriconi, M., Di Menno, M., R. Casale, G., and Siani, A. M.: Spectral Ultraviolet Measurements by a Multichannel Monitor and a Brewer Spectroradiometer: A Field Study, Radiat. Prot. Dosim., 102, 259-263, 2002.

di Sarra, A., Disterhoft, P., and DeLuisi, J.: On the Importance of Spectral Responsivity of Robertson-Berger type Ultraviolet Radiometers for Long-term Observations, Photochem. Photobiol., 76, 64-72, 2002.

Diémoz, H. and Mayer, B.: UV radiation in a mountaineous terrain: comparison of accurate 3D and fast $1 \mathrm{D}$ calculations in terms of UV index, in: Proceedings UV conference, Davos, Switzerland, 18-20 September 2007, 165-166, 2007.

Early, E. A., Thompson, E. A., and Disterhoft, P.: Field Calibration Unit for Ultraviolet Spectroradiometers, Appl. Optics, 37, 66646670, 1998.

Glandorf, M., Arola, A., Bais, A., and Seckmeyer, G.: Possibilities to detect trends in spectral UV irradiance, Theor. Appl. Climatol., 81, 33-44, 2005.

Gröbner, J. and Meleti, C.: Aerosol optical depth in the UVB and visible wavelength range from Brewer spectrophotometer direct irradiance measurements: 1991-2002, J. Geophys. Res., 109, D09202, doi:10.1029/2003JD004409, 2004.

Gröbner, J. and Sperfeld, P.: Direct traceability of the portable QASUME irradiance scale to the primary irradiance standard of the PTB, Metrologia, 42, 134-139, 2005.

Gröbner, J., Schreder, J., Kazadzis, S., Bais, A. F., Blumthaler, M., Görts, P., Tax, R., Koskela, T., Seckmeyer, G., Webb, A., and Rembges, D.: Traveling reference spectroradiometer for routine quality assurance of spectral solar ultraviolet irradiance measurements, Appl. Optics, 44, 5321-5331, 2005.

Gröbner, J., Blumthaler, M., Kazadzis, S., Bais, A., Webb, A., Schreder, J., Seckmeyer, G., and Rembges, D.: Quality assurance of spectral solar UV measurements: results from $25 \mathrm{UV}$ monitoring sites in Europe, 2002 to 2004, Metrologia, 43, 6671, 2006.

Gröbner, J., Hülsen, G., Wuttke, S., Schrems, O., De Simone, S., Gallo, V., Rafanelli, C., Petkov, B., Vitale, V., Edvardsen, K., and Stebel, K.: Quality assurance of solar UV irradiance in the Arctic, Photochem. Photobio. Sci., 9, 384-391, doi:10.1039/B9PP00170K, 2010.

Hülsen, G. and Gröbner, J.: Characterization and calibration of ultraviolet broadband radiometers measuring erythemally weighted irradiance, Appl. Optics, 46, 5877-5886, 2007.

Ialongo, I., Buchard, V., Brogniez, C., Casale, G. R., and Siani, A. M.: Aerosol Single Scattering Albedo retrieval in the UV range: an application to OMI satellite validation, Atmos. Chem. Phys., 10, 331-340, doi:10.5194/acp-10-331-2010, 2010.

Kerr, J. B., McElroy, C. T., and Olafson, R. A.: Measurements of ozone with the Brewer spectrophotometer, in: Proceedings of the Quadrennial International Ozone Symposium, 74-79, 1980.

Lantz, K., Disterhoft, P., Slusser, J. R., Gao, W., Berndt, J., Bernhard, G., Bloms, S., Booth, R., Ehramjian, J., Harrison, L., Janson, G., Johnston, P., Kiedron, P., McKenzie, R., Kimlin, M. G., Neale, P., O’Neill, M., Quang, V. V., Seckmeyer, G., Taylor, T., Wuttke, S., and Michalsky, J.: 2003 North American interagency intercomparison of ultraviolet spectroradiometers : scanning and spectrograph instruments, J. Appl. Remote Sens., 2, 1-33, 2008.

Lee-Taylor, J. M., Madronich, S., Fischer, C., and Mayer, B.: A climatology of UV radiation, 1979-2000, in: UV radiation in 
global climate change: measurements, modeling and effects on ecosystems, Tsinghua University Press, 2010.

Leszczynski, K., Jokela, K., Ylianttila, L., Visuri1, R., and Blumthaler, M.: Erythemally Weighted Radiometers in Solar UV Monitoring: Results from the WMO/STUK Intercomparison, Photochem. Photobiol., 67, 212-221, 1998.

Madronich, S.: UV radiation in the natural and perturbed atmosphere, in: Environmental Effects of Ultraviolet Radiation, Lewis, Boca Raton, Fla., 17-69, 1993.

Mateos, D., di Sarra, A., Meloni, D., Di Biagio, C., and Sferlazzo, D. M.: Experimental determination of cloud influence on the spectral UV irradiance and implications for biological effects, J. Atmos. Sol.-Terr. Phy., 73, 1739-1746, doi:10.1016/j.jastp.2011.04.003, 2011.

Mayer, B. and Kylling, A.: Technical note: The libRadtran software package for radiative transfer calculations - description and examples of use, Atmos. Chem. Phys., 5, 1855-1877, doi:10.5194/acp-5-1855-2005, 2005.

McKenzie, R. L., Aucamp, P. J., Bais, A., Björn, L. O., Ilyas, M., and Madronich, S.: Ozone depletion and climate change: impacts on UV radiation, Photoch. Photobio. Sci., 10, 182-198, 2011.

Meloni, D., Casale, G. R., Siani, A. M., Palmieri, S., and Cappellani, F.: Solar UV Dose Patterns in Italy, Photochem. Photobiol., 71, 681-690, 2000.

Petkov, B., Vitale, V., Tomasi, C., Bonafé, U., Scaglione, S., Flori, D., Santaguida, R., Gausa, M., Hansen, G., and Colombo, T.: Narrow-band filter radiometer for ground-based measurements of global UV solar irradiance and total ozone, Appl. Optics, 45, 4383-4395, 2006.

Schreder, J., Blumthaler, M., and Huber, M.: Design of an input optic for solar UV measurement, Internet Photochem. Photobiol., available at: http://www.photobiology.com/UVR98/schreder/index.htm (last access: 29 August 2011), 1998.

Seckmeyer, G., Bais, A., Bernhard, G., Blumthaler, M., Booth, C. R., Disterhoft, P., Eriksen, P., McKenzie, R. L., Miyauchi, M., and Roy, C.: Instruments to Measure Solar Ultraviolet Radiation, Part 1: Spectral Instruments, Tech. rep., World Meteorological Organization - Global Atmospherere Watch, 2001.

Seckmeyer, G., Bais, A., Bernhard, G., Blumthaler, M., Booth, C. R., Lantz, K., and McKenzie, R. L.: Instruments to Measure Solar Ultraviolet Radiation, Part 2: Broadband Instruments Measuring Erythemally Weighted Solar Irradiance, Tech. rep., World Meteorological Organization - Global Atmospherere Watch, 141, 2008a.
Seckmeyer, G., Pissulla, D., Glandorf, M., Henriques, D.and Johnsen, B., Webb, A., Siani, A. M., Bais, A., Kjeldstad, B., Brogniez, C., Lenoble, J., Gardiner, B., Kirsch, P., Koskela, T., Kaurola, J., Uhlmann, B., Slaper, H., Den Outer, P., Janouch, M., Werle, P., Gröbner, J., Mayer, B., De La Casiniere, A., Simic, S., and Carvalho, F.: Variability of UV Irradiance in Europe, Photochem. Photobiol., 84, 172-179, 2008 b.

Seckmeyer, G., Smolskaia, I., Pissulla, D., Bais, A. F., Tourpali, K., Meleti, C., and Zerefos, C.: Solar UV: Measurements and Trends, in: Twenty Years of Ozone Decline, edited by: Zerefos, C., Contopoulos, G., and Skalkeas, G., Springer Netherlands, 359-368, 2009.

Siani, A. M., Casale, G. R., Diémoz, H., Agnesod, G., Kimlin, M. G., Lang, C. A., and Colosimo, A.: Personal UV exposure in high albedo alpine sites, Atmos. Chem. Phys., 8, 3749-3760, doi:10.5194/acp-8-3749-2008, 2008.

Siani, A. M., Casale, G. R., Sisto, R., Borra, M., Kimlin, M. G., Lang, C. A., and Colosimo, A.: Short-term UV Exposure of Sunbathers at a Mediterranean Sea Site, Photochem. Photobiol., 85, 171-177, 2009.

Stamnes, K., Slusser, J., and Bowen, M.: Derivation of total ozone abundance and cloud effects from spectral irradiance measurements, Appl. Optics, 30, 4418-4426, 1991.

UNEP: Environmental effects of ozone depletion and its interactions with climate change: 2010 assessment, Tech. rep., United Nations Environment Programme, 2010.

Vanicek, K., Frei, T., Litynska, Z., and Schmalwieser, A.: UV-Index for the Public, a guide for publication and interpretation of solar UV Index forecasts for the public prepared by the Working Group 4 of the COST-713 Action UVB Forecasting, 1999.

Webb, A., Gröbner, J., and Blumthaler, M.: A practical guide to operating broadband instruments measuring erythemally weighted irradiance, available at: www.cost726.org (last access: $29 \mathrm{Au}-$ gust 2011) 2006.

Webb, A. R., Slaper, H., Koepke, P., and Schmalwieser, A. W.: Know Your Standard: Clarifying the CIE Erythema Action Spectrum, Photochem. Photobiol., 87, 483-486, 2011.

Williams, J. E., den Outer, P. N., and Slaper, H.: Quality assurance of solar spectral UV-measurements: methods and use of the SHICrivm software tool, in: EGS - AGU - EUG Joint Assembly, 2003.

WMO: Scientific assessment of ozone depletion: 2010, Tech. rep., World Meteorological Organization, Global Ozone Research and Monitoring Project, 2011. 